\title{
Study the Association Between Diet Program on Human Semen, Biological Profile, and Anthropometric Measurements in Obese Men
}

\author{
Asmaa Fathi Hamouda ${ }^{1,2, *}$, Saad El-Dien Abdel Fattah Abou El Noeman ${ }^{3}$, \\ Ibrahim Abdu Khardalic ${ }^{4}$, Magbool Essa Oraiby ${ }^{4}$ \\ ${ }^{1}$ Department of Biochemistry, Faculty of Science, University of Alexandria, Alexandria, Egypt \\ ${ }^{2}$ Medical Laboratory Technology Department, Faculty of Applied Health Sciences, Jazan University, Jazan, Kingdom of Saudi Arabia \\ ${ }^{3}$ Department of Medical Biochemistry, Faculty of Medicine, University of Tanta, Tanta, Egypt \\ ${ }^{4}$ Poison Control and Medical Forensic Chemistry Center, Ministry of Health, Jazan, Kingdom of Saudi Arabia
}

Email address:

asmaakingdom1@yahoo.com (A. F. Hamouda)

${ }^{*}$ Corresponding author

\section{To cite this article:}

Asmaa Fathi Hamouda, Saad El-Dien Abdel Fattah Abou El Noeman, Ibrahim Abdu Khardalic, Magbool Essa Oraiby. Study the Association Between Diet Program on Human Semen, Biological Profile, and Anthropometric Measurements in Obese Men. International Journal of Nutrition and Food Sciences. Vol. 7, No. 1, 2018, pp. 24-29. doi: 10.11648/j.ijnfs.20180701.14

Received: November 26, 2017; Accepted: December 4, 2017; Published: January 2, 2018

\begin{abstract}
Obesity has grown leading global health issues owing to its strong association with a high incidence of diseases that including male infertility. Infertility is the disability of a sexually active, non-contracepting couple to achieve pregnancy and reproduce. Congenital factors, acquired urogenital abnormalities, urogenital tract infections, endocrine disturbances, genetic abnormalities, immunological factors, obesity and lifestyle factors are among of infertility causes. Seminal analysis and serum levels of testosterone (T), luteinizing hormone (LH), follicle stimulating hormone (FSH) thyroid-stimulating hormone (TSH), Triiodothyronine (T3), Thyroxine (T4) as well as biological profile and anthropometric measurements in obese men evaluated before and after six-month weight loss programme as compared with baseline and reference range. There is a significant reduction in weight and high improvement semen, hormonal, biological profile and anthropometric measurements as compared to the reference range. The results may be due to the combination of the weight loss and improved nutrition.
\end{abstract}

Keywords: Anthropometric Measurements, Hormonal Biological, Human Semen, Infertility, Obesity

\section{Introduction}

Obesity is excess fat tissue in the body and current day severe co-morbidities that result from bad lifestyle, energy dense food, lack of physical activity, and genetic susceptibility that interact with the environmental factor. Obesity and other factors cause infertility that including sexually transmitted disease, genetic, DNA damage, diabetes mellitus, thyroid disorders, pituitary factors and other [1-2]. The male reproductive endocrine systems including hypothalamus induce the secretion of gonadotropin-releasing hormone $(\mathrm{GnRH})$ which stimulates anterior pituitary. Therefore, anterior pituitary gland produces the secretion of follicle-stimulating hormone (FSH) which involves in sperm maturation and luteinizing hormone (LH) which stimulates the production and secretion of testosterone [1-4]. The Diet, lifestyle and nutritional balance can influence a man's fertility [5-10]. The aim of this work is to evaluate the effect of safe six-month weight loss program on human semen and the biological profile.

\section{Subjects and Methods}

(1) Subjects: A total of 15 adults' males Egyptian obese included in this study. The investigations did according to Helsinki Declaration. Participants supported a comprehensive series of biochemical, anthropometrical, and nutritional before treatment- at baseline and after the 6-month. 
(2) Anthropometrics: The subjects' weights and heights were estimated monthly on a single calibrated scale (SRScales, SR Instruments). The remain measurements collected monthly for six months involved waist size, Neck, Hip and self-reported medical history. Anthropometric parameters took while the subjects were standing erect and barefoot. Height and weight were included using standardized conventional methods. Body mass index (BMI) determined by the formula: weight in kilograms $(\mathrm{kg})$ divided by height in square meters (m2). The Body Fat (\%) estimated by the method of U. S. Navy. Waist circumference WC $(\mathrm{cm})$, the belly body fat $=$ waist: hip ratio.

(3) Laboratory investigations: Semen samples analyzed according to World Health Organization guidelines [4].

Reproductive Hormones: one nonfasting blood specimen was drawn between 0900 and 1600 hours on the same day that the semen sample was collected. Blood was withdrawn following an overnight fast ( $>9$ hours) for serum AST, ALT, total bilirubin, albumin, creatinine, uric acid, triglyceride, total cholesterol, HDL cholesterol, LDL cholesterol measuring using standard Roche/Hitachi Cobas c 501 analyzers (Roche Diagnostics, Mannheim, Germany). Serum TSH, T3, T4, LH, FSH, and testosterone were determined to utilize commercially ready materials by Roche/Hitachi Cobas e 601 analyzers (Roche Diagnostics, Mannheim, Germany) using electrochemiluminescence immunoassay.

(4) Statistic: Data analyzed using IBM SPSS software package version 20.0.

(5) The diet program: Diet in details according to a program of Hamouda and Abou El Noeman, 2016 [5, 6] and the complete study and details demonstrated in my book OBESITY AND MALE INFERTILITY [6].

The subject accompanied separate lectures, group and individual lessons, for one hour weekly supported by PowerPoint show for six months; all speeches given by authorities in nutritional counseling and psychological assistance (counseling group support). Subjects obtained an overview diet handout, instructional nutrition labels, sample menus as well as methods.

The suggested diet program in this study is different from repeated dietary slogan because it is not dependent on a calorie. I understand a calorie is a calorie, but the presented program does not dependent on calorie especially in first two months. The program depends on the type and the biochemical reaction of food with human body regardless calorie and amount of food; with the passage of time, the patient adapted to decrease the amount of food step by step as well as drop both addictive to eat unhealthy food and craving experiences. The aim of the diet program reduced manufactured, industrial food and increased Nature food, to attain therapeutic nutrition goal, reduce hunger and progressed satiety, and diminish the energy density food that used at baseline. The subjects taught different dietary strategies to achieve this aim; each human is unique.

The diet strategies as follows:

Daily: The subject advice to drink one cup of water every morning and 2.5 liters of water throughout the day. Eating seven pieces of seasonal fresh fruits and vegetables from all color every day is essential. Whole grain wheat or oat plus milk or seven dates or one pomegranate or kiwi or green apple or part of watermelon with their seeds as well as loupe plus coconut or tomato or orange juices at morning and before every meal, each type for a week and change according to harvesting season is important. Eating fifteen unroasted almonds mainly at afternoon is every day. Ginger, or cinnamon, or green tea after lunch alternatively. 3-4 teaspoons of olive oil, 1/8 teaspoons of curcumin on food plus garlic and onions are daily critical. Popcorn eating is without fat as well as any fresh seasonal fruits and vegetables for a snack. Cup of yogurt contains 2-3 teaspoons of bee honey take mainly before dinner as well as any amount of popcorn without fat for dinner. Use Earlier sleep two spoons of cocoa bean with milk are also essential.

Weekly: Protein serving is fish grilled or baked and tuna, salmon, or any oily fish five times per week. In addition, lentil meal is 2-3 per week plus onion and garlic.

Avoid brassica vegetables such as cabbage, cauliflower, broccoli, potatoes and turnip inpatient that registered the small rise in TSH at baseline intervention for a month is basic advice.

Individual lessons: The subjects introduced written supplies and individual learning from us. To achieve back to Nature diet, a person, guided in cooking and recipe. Subjects also educated about suggested food type and serving sizes but encouraged to eat big, pleasant servings of low-energydensity foods (fruit, vegetables, nuts, and fruit or natural vegetable juice). We also supported eat serving sizes of medium- and high-energy-density foods each weekend as a free day to bypass fixed in metabolism. Behavioral healing plan for the patient, increasing self-efficacy for lifestyle modifications, such as goal setting and social support deal with emotional eating, stress, overcoming hindrances, problem-solving. There is no physical activity knowledge for subjects. Subjects recorded their appetite at months 0, 6 and learned how to reached satiety.

\section{Results}

Tables 1 show the general characteristics of both cases baseline characteristics of enrolled male infertile obese 15 subjects before and after 6-months of intervention. The sperm concentration of the study population including volume, count and total count illustrated in Table 1. There was significant difference in the mean of volume $(\mathrm{ml})$, sperm concentration $(\mathrm{ml})$ and total sperm count/ejaculation before $\left(2.0 \pm 0.0(\mathrm{~mL}), 56.4 \times 10^{5} \pm 9.5 \times 104(\mathrm{~mL}), 11.2 \times 10^{6} \pm\right.$ $98.6 \times 103$ ) respectively, and after the 6-month intervention $\left(3.0 \pm 0.0(\mathrm{ml}), 19.2 \times 10^{6} \pm 94.1 \times 103(\mathrm{ml}), 57.6 \times 10^{6} \pm\right.$ $13.6 \times 10^{4}$ ) respectively, at $<0.001$ (Table 1) while Lower reference limit according to WHO (Semen volume $(\mathrm{mL})=$ 1.5 (1.4-1.7), Sperm concentration $\left(10^{6}\right.$ per $\left.\mathrm{mL}\right) 15$ (12-16) and Total sperm number $\left(10^{6}\right.$ per ejaculate) 39 (33-46).

Table 1 summarizes the sperm motility (\%) that included the total motility, and type of motility of the study population 
at $<0.001$. The results showed a significant difference in the mean of the sperm motility after $30 \mathrm{~min}, 1$ hour, before $(10.47 \pm 0.83 \%, 5.13 \pm 0.35 \%$, and the 6-month intervention $(30.0 \pm 0.0 \%, 24.64 \pm 1.34 \%)$. There was significant difference in the mean of sperm type of motility Immotile (IM) before $(90.33 \pm 0.62 \%)$, and after 6-month of intervention $(70.0 \pm 0.0 \%)$. The sperm total motility (progressive motility $\mathrm{PR}+$ non-progressive motility NP\%) also showed significant difference in the mean before $(9.67 \pm$ $0.62 \%)$ and after 6 - month of intervention (30.0 $\pm 0.0 \%)$. Progressive motility (PR) and non-progressive motility (NP) showed a significant difference in the mean before $(0.0 \pm$ $0.0 \%, 9.67 \pm 0.62 \%)$ and after 6 -month of intervention $(24.93$ $\pm 0.26 \%, 5.07 \pm 0.26 \%$ ) respectively. While Lower reference limit according to WHO (Total motility (Progressive and Non-progressive $\%=[40(38-42)]$, Progressive motility $(\%)=$ [32 (31-34)]).

There is a significant difference in the mean of the total abnormal forms of sperm (\%) according to Kruger's classification before $(90.47 \pm 0.52)$ and after 6-month of intervention $(66.0 \pm 0.0)$ at $<0.001$ (Table 1). As well as significant mean of abnormal head forms and tail abnormalities showed before $(55.27 \pm 16.17 \%$ and $14.67 \pm$ $6.98 \%)$ and after 6-month of intervention $(8.0 \pm 0.0 \%, 29.0 \pm$ $0.0 \%$ respectively at $<0.001$ (Table 1 ). There is a significant mean of mid-portion abnormalities showed before $(20.60 \pm$ $9.20 \%)$ and after 6 -month of intervention $(29.0 \pm 0.0 \%)$ at $<$ 0.003 (Table 1). While Lower reference limit according to WHO Sperm morphology (normal forms, \%) = 4 (3.0-4.0).

There was significant difference in the mean AST at 0.003 and ALT at 0.002 , before $(29.20 \pm 6.52 \mathrm{U} / \mathrm{L}, 38.13 \pm$ $14.81 \mathrm{U} / \mathrm{L})$ respectively, and after the 6-month intervention $(24.40 \pm 4.21 \mathrm{U} / \mathrm{L}, 26.07 \pm 5.57 \mathrm{U} / \mathrm{L})$ respectively (Table 1$)$, while reference range $(\mathrm{AST}$ : Male $=$ up to $35.0 \mathrm{U} / \mathrm{L}$, ALT, Male $=$ up to $41.0 \mathrm{U} / \mathrm{L})$. Otherwise there was significant difference in the mean T. Bilirubin and Albumin before $(0.50$ $\pm 0.11 \mathrm{mg} / \mathrm{dl}, 4.15 \pm 0.24 \mathrm{~g} / \mathrm{dl})$ respectively, and after the 6 month intervention $(0.41 \pm 0.05 \mathrm{mg} / \mathrm{dl}, 3.93 \pm 0.30 \mathrm{~g} / \mathrm{dl})$ respectively, at 0.002 (Table 1) while reference range (Bilirubin: Male = up to $1.4 \mathrm{mg} / \mathrm{dl}$, Albumin: $3.5-5.2 \mathrm{~g} / \mathrm{dl}$ ).

There was significant difference also in the mean creatinine and uric acid before $(0.90 \pm 0.15 \mathrm{mg} / \mathrm{dl}, 6.01 \pm$ $0.81 \mathrm{mg} / \mathrm{dl})$ respectively, and after the 6-month intervention $(0.76 \pm 0.14 \mathrm{mg} / \mathrm{dl}, 4.85 \pm 0.82 \mathrm{mg} / \mathrm{dl})$ respectively, at 0.001 (Table 1) while reference range (Creatinine: $\mathrm{M}=0.6-1.4$ $\mathrm{mg} / \mathrm{dl})$, Uric acid: $\mathrm{M}=3.0-7.0 \mathrm{mg} / \mathrm{dl})$ ).
Serum lipids profile showed a significant difference in the mean T-cholesterol at 0.002, Triglyceride, HDL cholesterol and LDL cholesterol before $(196.87 \pm 17.04 \mathrm{mg} / \mathrm{dl}, 154.0 \pm$ $8.86 \mathrm{mg} / \mathrm{dl}, 34.27 \pm 3.20 \mathrm{mg} / \mathrm{dl}, 125.80 \pm 11.42$,) respectively, and after the 6-month intervention $(179.60 \pm 17.50 \mathrm{mg} / \mathrm{dl}$ $112.13 \pm 6.38 \mathrm{mg} / \mathrm{dl}, 38.11 \pm 3.25 \mathrm{mg} / \mathrm{dl}, 108.47 \pm 7.29$ $\mathrm{mg} / \mathrm{dl}$ ) respectively, at $<0.001$ (Table 1) while reference range (T-cholesterol: $140-200 \mathrm{mg} / \mathrm{dl}$, Triglyceride: $<200$ $\mathrm{mg} / \mathrm{dl}$, HDL cholesterol: $\mathrm{M}=33-55 \mathrm{mg} / \mathrm{dl}$, LDL cholesterol: Up to $100 \mathrm{mg} / \mathrm{dl}$ ).

There was significant difference in the mean TSH, T3, and $\mathrm{T} 4$ before $(5.02 \pm 0.40 \mu \mathrm{IU} / \mathrm{ml}, 1.03 \pm 0.07 \mathrm{ng} / \mathrm{ml}, 8.38 \pm$ $0.66 \mu \mathrm{g} / \mathrm{dl})$ respectively, and after the 6-month intervention $(4.20 \pm 0.30 \mu \mathrm{IU} / \mathrm{ml}, 1.60 \pm 0.25 \mathrm{ng} / \mathrm{ml}, 9.82 \pm 0.50 \mu \mathrm{g} / \mathrm{dl})$ respectively, at $<0.001$ (Table 1 ) while reference range (TSH, $\mathrm{T} 3$, and T4 upper normal 0.270-4.20 $\mu \mathrm{IU} / \mathrm{mL}, 0.8-2.0 \mathrm{ng} / \mathrm{ml}$. $5.1-14.1 \mu \mathrm{g} / \mathrm{dl}$ respectively).

There was significant difference in the mean FSH, $\mathrm{LH}$, and Testosterone before $(8.89 \pm 0.05 \mathrm{mIU} / \mathrm{ml}, 9.87 \pm 0.35 \mathrm{mIU} /$ $\mathrm{ml}, 4.07 \pm 0.04 \mathrm{ng} / \mathrm{ml})$ respectively, and after the 6-month intervention $(7.77 \pm 0.30 \mathrm{mIU} / \mathrm{ml}, 7.18 \pm 0.33 \mathrm{mIU} / \mathrm{ml}, 6.07$ $\pm 0.48 \mathrm{ng} / \mathrm{ml}$ ) respectively, at $<0.001$ (Table 1) while reference range $\mathrm{FSH}, \mathrm{LH}$, and Testosterone, $\mathrm{M}$ : $0.6-0.9$ $\mathrm{mIU} / \mathrm{ml}, \mathrm{M}: \quad 0.5 \quad-5.6 \mathrm{mIU} / \mathrm{ml}, \mathrm{M}\left(\begin{array}{llll}3.0 & -10.0 & \mathrm{ng} / \mathrm{ml}\end{array}\right.$ respectively).

Anthropometric parameters showed a significant difference in the mean weight, BMI, WC, and body fat before $(151.67 \pm 6.29 \mathrm{~kg}, 46.64 \pm 2.75 \mathrm{~kg} / \mathrm{m} 2,1.06 \pm 0.04 \mathrm{~cm}, 44.37$ $\pm 1.75 \%$ ) respectively, and after the 6 -month intervention $(114.20 \pm 5.44 \mathrm{~kg}, 35.30 \pm 2.46 \mathrm{~kg} / \mathrm{m} 2,0.97 \pm 0.04 \mathrm{~cm}, 38.13$ $\pm 2.81 \%$ ) respectively, at $<0.001$ (Table 1), while World Health Organization's (WHO) recommended BMI for adult normal range $18.5-25 \mathrm{~kg} / \mathrm{m} 2$, Overweight $25-30 \mathrm{~kg} / \mathrm{m} 2$, Obese Class I $30-35 \mathrm{~kg} / \mathrm{m} 2$, Obese Class II $35-40 \mathrm{~kg} / \mathrm{m} 2$, Obese Class III $>40 \mathrm{~kg} / \mathrm{m} 2$ respectively, while reference range in men the visceral body fat should be 1.0 or less, as well as recommended amount body fat for normal male 8$14 \%$, Obese male $>25 \%$ respectively.

Table 2 show correlation analyzes between selected parameters. Pearson's correlations were performed to investigate the possible associations between parameters. There is a negative correlation between BMI with testosterone and total sperm count as well as T3 (Table 2). There is a positive correlation between $\mathrm{T} 4$ and sperm motility as well as a negative correlation between LH with Total sperm count (Table 2).

Table 1. Comparison between baseline and after according to different parameters ( $n=15)$.

\begin{tabular}{|c|c|c|c|c|}
\hline & Baseline & After & $\mathbf{P}$ & Reference Range \\
\hline 1- Examination of Seminal Fluid & & & & $\begin{array}{l}\text { Lower reference limit of } \\
\text { semen according to WHO }\end{array}$ \\
\hline Volume (ml) & $2.0 \pm 0.0$ & $3.0 \pm 0.0$ & & $1.5(1.4-1.7)$ \\
\hline Reaction $\mathrm{Ph}$ & $8.0 \pm 0.0$ & $8.0 \pm 0.0$ & & $>7.2$ \\
\hline Sperm concentration $(\mathrm{ml})$ & $56.4 \times 10^{5} \pm 9.5 \times 10^{4}$ & $19.2 \times 10^{6} \pm 94.1 \times 10^{3}$ & $<0.001^{*}$ & $\left(10^{6} / \mathrm{mL}\right) 15(12-16)$ \\
\hline Total sperm count/ejaculation & $11.2 \times 10^{6} \pm 98.6 \times 10^{3}$ & $57.6 \times 10^{6} \pm 13.6 \times 10^{4}$ & $<0.001^{*}$ & $\left(10^{6} /\right.$ ejaculate) $39(33-46)$ \\
\hline \multicolumn{5}{|l|}{ Motility (\%) } \\
\hline After $30 \mathrm{~min}(\mathrm{PR}+\mathrm{NP} \%)$ & $10.47 \pm 0.83$ & $30.0 \pm 0.0$ & $<0.001^{*}$ & \\
\hline After 1 hour (PR+NP\%) & $5.13 \pm 0.35$ & $24.64 \pm 1.34$ & $<0.001^{*}$ & \\
\hline Sperm type of motility & & & & \\
\hline
\end{tabular}




\begin{tabular}{|c|c|c|c|c|}
\hline & Baseline & After & $\mathbf{P}$ & Reference Range \\
\hline Immotile (IM) & $90.33 \pm 0.62$ & $70.0 \pm 0.0$ & $<0.001^{*}$ & \\
\hline Total motility $(\mathrm{PR}+\mathrm{NP} \%)$ & $9.67 \pm 0.62$ & $30.0 \pm 0.0$ & $<0.001^{*}$ & $40(38-42)$ \\
\hline Progressive motility (PR) & $0.0 \pm 0.0$ & $24.93 \pm 0.26$ & $<0.001^{*}$ & $32(31-34)$ \\
\hline Non progressive motility (NP) & $9.67 \pm 0.62$ & $5.07 \pm 0.26$ & $<0.001^{*}$ & \\
\hline \multicolumn{5}{|c|}{ Abnormal form according to Kruger's classification } \\
\hline Total abnormal forms $(\%)$ & $90.47 \pm 0.52$ & $66.0 \pm 0.0$ & $<0.001^{*}$ & \\
\hline Abnormal head forms & $55.27 \pm 16.17$ & $8.0 \pm 0.0$ & $<0.001^{*}$ & \\
\hline Tail abnormalities & $14.67 \pm 6.98$ & $29.0 \pm 0.0$ & $<0.001^{*}$ & \\
\hline \multicolumn{5}{|l|}{ 2- Serum Biological Profile } \\
\hline $\mathrm{FSH}(\mathrm{mIU} / \mathrm{ml})$ & $8.89 \pm 0.05$ & $7.77 \pm 0.30$ & $<0.001^{*}$ & $0.6-0.9$ \\
\hline $\mathrm{LH}(\mathrm{mIU} / \mathrm{ml})$ & $9.87 \pm 0.35$ & $7.18 \pm 0.33$ & $<0.001^{*}$ & $0.5-5.6$ \\
\hline Testosterone (ng/ ml) & $4.07 \pm 0.04$ & $6.07 \pm 0.48$ & $<0.001^{*}$ & $3.0-10.0$ \\
\hline $\mathrm{TSH}(\mu \mathrm{IU} / \mathrm{ml})$ & $5.02 \pm 0.40$ & $4.20 \pm 0.30$ & $<0.001^{*}$ & $0.270-4.20$ \\
\hline Total T3 (ng/ml) & $1.03 \pm 0.07$ & $1.60 \pm 0.25$ & $<0.001^{*}$ & $0.8-2.0$ \\
\hline $\operatorname{ALT}(\mathrm{U} / \mathrm{L})$ & $38.13 \pm 14.81$ & $26.07 \pm 5.57$ & $0.002^{*}$ & Up to 41.0 \\
\hline S. T. Bilirubin (mg/dl) & $0.50 \pm 0.11$ & $0.41 \pm 0.05$ & $0.002^{*}$ & Up to 1.4 \\
\hline S. Albumin $(\mathrm{g} / \mathrm{dl})$ & $4.15 \pm 0.24$ & $3.93 \pm 0.30$ & $0.002^{*}$ & $3.5-5.2$ \\
\hline S. Creatinine (mg/dl) & $0.90 \pm 0.15$ & $0.76 \pm 0.14$ & $<0.001^{*}$ & $0.6-1.4$ \\
\hline S. Uric acid (mg/dl) & $6.01 \pm 0.81$ & $4.85 \pm 0.82$ & $<0.001^{*}$ & $3.0-7.0$ \\
\hline S. T-cholesterol (mg/dl) & $196.87 \pm 17.04$ & $179.60 \pm 17.50$ & $0.002^{*}$ & $140-200$ \\
\hline S. Triglceride (mg/dl) & $154.0 \pm 8.86$ & $112.13 \pm 6.38$ & $<0.001^{*}$ & $<200$ \\
\hline S. HDL cholesterol (mg/dl) & $34.27 \pm 3.20$ & $38.11 \pm 3.25$ & $<0.001^{*}$ & $33-55$ \\
\hline S. LDL cholesterol (mg/dl) & $125.80 \pm 11.42$ & $108.47 \pm 7.29$ & $<0.001^{*}$ & Up to 100 \\
\hline \multicolumn{5}{|l|}{ 3- Anthropometric Measurements } \\
\hline Weight (kg) & $151.67 \pm 6.29$ & $114.20 \pm 5.44$ & $<0.001 *$ & \\
\hline $\mathrm{BMI}\left(\mathrm{kg} / \mathrm{m}^{2}\right)$ & $46.64 \pm 2.75$ & $35.30 \pm 2.46$ & $<0.001^{*}$ & $18.5-25$ \\
\hline WC $(\mathrm{cm})$ Waist circumference $(\mathrm{cm}$ & $1.06 \pm 0.04$ & $0.97 \pm 0.04$ & $<0.001^{*}$ & 1.0 or less \\
\hline $\mathrm{BF}(\%)$ & $44.37 \pm 1.75$ & $38.13 \pm 2.81$ & $<0.001 *$ & $8-14$ \\
\hline
\end{tabular}

Data expressed in mean $\pm \mathrm{SD}, *$ : Statistically significant at $\mathrm{p} \leq 0.05$.

Table 2. Correlation between different studied parameters.

\begin{tabular}{lll}
\hline & R & $\mathbf{p}$ \\
\hline Total sperm count/ejaculation VS BMI after & $-0.522^{*}$ & 0.046 \\
Motility30min VS T4 baseline & $0.632^{*}$ & 0.012 \\
Total sperm count VS LH after & $-0.677^{*}$ & 0.006 \\
Total T3 (ng/ml) VS BMI baseline & -0.072 & 0.799 \\
Total T3 (ng/ml) VS BMI after & -0.275 & 0.321 \\
Testosterone (ng/ ml) VS BMI baseline & -0.279 & 0.313 \\
\hline
\end{tabular}

r: Pearson coefficient

*: Statistically significant at $\mathrm{p} \leq 0.05$.

\section{Discussion}

The present study showed significant improvements in seminal, hormonal, biological profiles and anthropometric measurements in 15 obese men after six-month weight loss program compared with baseline and reference range [6]. A recent study reported that increased BMI associated with reduced levels of, testosterone that required for semen quality due to aromatization $[1,4,6-8]$. Men with body mass index (BMI) more than 25 or lower than $18.5 \mathrm{~kg} / \mathrm{m} 2$ show that less breeding than men of healthy weight. Men with abnormal BMI produces lower sperm counts, and less sperm quality that may be an increase of heat around the genital zone led to increasing of oxidative stress and sperm DNA damage [1, 5, 6]. Several studies documents that raised male BMI correlated with diminished plasma concentrations of sex hormone coupling globulin (SHBG) and testosterone, an increase in plasma concentration of estrogen that linked with subfertility. The hormone imbalance diminished sperm counts by interrupting the negative feedback loop of the hypothalamic pituitary gonadal (HPG) axis. Otherwise, the asymmetry of hormone implicated in the regulation of Sertoli cell function and spermatogenesis, such as FSH/LH ratios that have observed to be decreased in males with higher BMI. Targeted interruption of FSH affects gametogenesis and hormonal asymmetry. Male obesity connected with lower total and free testosterone extended [1, 11-13]. Also, previous studies reported that, the reduction in androgen levels is proportional to the degree of obesity $[1,11]$. The present results confirmed other previous reports and showed that there is a negative correlation between BMI with testosterone, total sperm count, and T3 that agree with the recent study that reported that increased BMI is associated with diminished levels of, testosterone that required for semen quality [12]. In the present study, also there is an association between BMI and improvement seminal and hormonal analysis that related to male infertility, so it is a substantial evidence prove the relation between obesity, body composition, and infertility.

In diet program advice to incorporate food rich in fruit, vegetable, whole grain, seed and nut supported as recovering fertility in obese men by decrease weight and heat around the scrotum and increase nutrient that enter in spermatogenesis and hormonal balance. Losing weight in the unsafe program is not useful for improving fertility because it deprives the 
body of the necessary proteins and fats required for hormone production and sperm generation [1-9]. The improvement in hormonal profile especially thyroid function that appears in results is due to removing brassica vegetables with increased in eating sea fish in subjects showed a slight elevation in $\mathrm{TSH}$ at baseline for a month. By eliminating the sources of thioglucosides, the most common goitrogens, as found in brassica vegetables that by yield hydrolysis thiocyanates and isothiocyanates which inhibit the selective concentration of iodine by the thyroid leading to amelioration in subject's metabolism $[5,6]$. The diet strategies improve the body start from intestinal bacteria by advice balance daily eating and symbiotics synergistic interaction. Including of water and water-rich foods into the offered diet can also decrease calories because water adds weight and volume to food without adding energy. Increasing the eating of seasonal fruit and vegetables, healthy fat and whole grains that are nutrient dense is also consistent with current dietary guidelines and is associated with the high diet quality. The explanation agrees with previous studies that found that phytochemistry and polyphenol compound present in fruit, vegetable, whole grain metabolized by the same way of metabolic detoxification method common to various xenobiotics that restricts their potential toxic effects. In addition, the phytochemistry has a role in the prevention of many diseases including infertility [5-10]. The Diet program contains vitamins, minerals protein, healthy fat, phytochemistry and dietary fiber. The vitamins act as an antioxidant to protect sperm oxidative stress and improve sperm motility. Furthermore, vitamins are essential in the metabolism and enter in sperm RNA and DNA synthesis as well as promote healthy growth of seminiferous tubule. Vitamins may work together to improve sperm capacity and concentration, as well as decreased the level of oxidative DNA destruction in the spermatozoa. Furthermore, minerals have antioxidant protection to spermatozoa cells against oxidative, free radical damage and death [5-10]. Diet also contents arginine, citrulline, taurine and carnitine that have a role in regulating the mechanisms underlying penile erection and have a role in power generation in mitochondria of sperm that affects both sperm count and motility [5-10]. The diet program [6] composition including phytochemistry and polyphenol that found in seasonal fruit and vegetables. The composition such as lycopene determines in high levels in the male testes and has an antioxidant effect and improving hormonal sexual level [9]. In addition, ellagic acid punicalagins, d-limonene dietary fibers have antioxidant, antiobesity that assistances fertility and testosterone levels. Diet contains healthy fat such as omega-3, essential oils, and phytosterols that enhance sperm quality and antioxidant effect. And oleuropein that increasing urinary noradrenaline and testicular testosterone hormone levels and decreasing plasma corticosterone level through activation thermogenesis process and reduce body weight [6] that regulated leptin hormonal mechanisms to reduce storage fat in the body and improve seminal quality [5-10]. And, that explained the improvement in semen, liver, kidney, lipid, hormone profiles as well as anthropometric measurements in obese adult subjects after six-month intervention as compared to baseline and reference data [6-11].

Advice to put fish with olive oil or lentils or oatmeal, as well as almond and coconut in patient diet, have a role to improve seminal parameter, lipid profile, liver and kidney function and anthropometric measurements of present studies. These results may be due to the composition of an amino acid such as carnitine, L-arginine taurine as well as healthy fat. Amino acid has the role of the metabolic methods to decrease obesity, balance hormones and power generation that fuel sperm motility, quality and it present in high levels in sperm cells [13-15].

Moreover, the scientist reported that weight loss could improve the reproductive indicators that agree with present finding that showed significant improvements in seminal parameters, hormonal and anthropometric measurements in 15 obese men after six-month weight loss programme compared with baseline and reference range. The diet program led to changes in the desire, craving, body weight and hormonal balance for the subject body by change guts bacteria where the gut is a house of disease, healing, and cures $[5,16]$. The advice to add bee honey to yogurt in a six-month diet program is an explanation for in improvement of present result. Such recommendation led to changes in the composition of the colonic microbiota, which modulation of the metabolism through symbiotics interaction. Both probiotic bacteria found in milk (lactobacilli and bifidobacteria) taken together with prebiotics found in honey and banana or other fruits (oligosaccharides and Fructo-oligosaccharides) collaborate in a synergistic. As well as led to balance intestinal bacteria, improved microbial balance resulted in induced satiety, enhanced barrier function, decreased inflammatory tone, decreased abdominal adiposity, decreased total cholesterol and control transit time [5-6, 16].

The present result showed an improvement, due to the diet influences male infertility by both direct and indirect ways to decrease obesity and increases nutrient that enters into sperm protection and formation. Such recommendation to added cinnamon, ginger, curcumin, cocoa bean separately in the subject diet help in (turn on) metabolism, decrease body fat and reduce weight so led to removing obesity- infertility causes. As well as getting benefit from their phytochemical contents that have anti-inflammatory, antioxidant and anticancer effects [17-20].

There is substantial evidence in present study improve that male obesity has adverse consequences on fertility through turns at hormonal levels, as well as direct conversions to sperm capacity, sperm number, and structure. Among the multiple of publications examined and studied review in this paper that showed that the diminished of spermatogenesis and sexual dysfunction is due to obesity and unhealthy lifestyle. Increased BMI found significantly associated with a fall in sperm count and serum testosterone. Reversibility of infertility is an excellent point which gives us as a severe challenge to follow the healthy lifestyle [21-26]. 


\section{Conclusion}

The synergistic effect of the natural composition of the present diet program works to improve semen, hormonal, biological profile and anthropometric measurements as compared to the baseline and the reference range. Because it is not, only a matter of gross weight, but it is also a deficiency in nutrients dense food as well as essential nutrients. The purpose of nutritional and biochemical administrators in reproduction and subfertility treatment is critical.

\section{Acknowledgements}

The authors appreciate Taymour-Lank M. Farawilla.

\section{References}

[1] Nicole OP, Hassan WB, Tod F and Michelle L. 2012. Impact of obesity on male fertility, sperm function and molecular composition. Spermatogenesis (2): 4, 253-263.

[2] Gharagozloo P, Aitken RJ. 2011. The role of sperm oxidative stress in male infertility and the significance of oral antioxidant therapy. Hum. Reprod 26 (7): 1628-40.

[3] Andreeva P. 2014. "[Thyroid gland and fertility] [Article in Bulgarian]". Akush Ginekol (Sofiia): 53 (7): 18-23.

[4] World Health Organization. WHO laboratory manual for the examination of human semen and sperm-cervical mucous interaction. 4th ed. Cambridge: Cambridge University Press, 1999.

[5] Hamouda FA, and Abou El Noeman SA. 2016. Effects of 6Month Weight Loss New Program on Anthropometric Measurements and Biological Profile. Journal of Pharmacy and Pharmacology. (4) 23-38.

[6] Asmaa F. Hamouda, and Saad El Dien A. Abou El Noeman. 2016. OBESITY AND MALE INFERTILITY. Scholars Press (ISBN 978-3-659-84033-3).

[7] Yunsang C, Wanxi Y. 2011. Functions of essential nutrition for high quality spermatogenesis. Advances in Bioscience and Biotechnology (2), 182-197.

[8] Claudine M, Augustin S, Christine M, Christian R, and Liliana J. 2004. Polyphenols: food sources and bioavailability. Am J Clin Nutr (79): 727-47.

[9] Damayanthi D, Ashok A, Chloe O, Pallavi P. Lycopene and male infertility 2014.. Asian Journal of Andrology (16), 420 425 .

[10] Rhoads J, Satterfield MC, Smith SB, Spencer TE, and Yin Y. 2009. Arginine metabolism and nutrition in growth, health and disease. Amino Acid (37), 153-168.

[11] Nazni P. 2014. Association of western diet \& lifestyle with decreased fertility. Indian J Med Res 140 (Supplement), pp 78-8.
[12] John DM, Linda GB, and RH. 2007. Relationships between Serum Hormone Levels and Semen Quality among Men from an Infertility Clinic. Journal of Andrology Vol. (28), No. 3.

[13] Cooper R, Hyppönen E, Berry D, Power C. 2010. Associations between parental and offspring adiposity up to midlife: the contribution of adult lifestyle factors in the 1958 British Birth Cohort Study. Am J Clin Nutr.: (92): 946-53.

[14] Wong WY, Flik G, Groenena PM, Swinkels DW, Thomas CM, Copius-Peereboom JHJ, Merkus HMWM, and SteegersTheunissen, RPM. 2011. The impact of calcium, magnesium, zinc, and copper in blood and seminal plasma on semen parameters in men. Reproduc-tive Toxicology (15), 131-136.

[15] Ng CM, Blackman MR, Wang C, and Swerdloff RS. 2004. The role of carnitine in the male reproductive system. Annals New York Academy of Sciences (1033), 177-188.

[16] Hakonsen LB, Thulstrup AM, Aggerholm AS, Olsen J, Bonde JP, Andersen CY, Bungum M, Ernst EH, Hansen ML, Ernst EH, and Ramlau-Hansen CH. 2011. Does Weight Loss Improve Semen Quality and Reproductive Hormones? Results from a cohort of severely obese men. Danish Ramazzini Center Reprod Health, 17 (8): 1-24.

[17] Yüce A, Türk G, Çeribaşi S, Sönmez M, Çiftçi M, Güvenç M. 2013. Effects of cinnamon (Cinnamomum zeylanicum) bark oil on testicular antioxidant values, apoptotic germ cell and sperm quality. Andrologia, 45 (4): 248-55.

[18] Carlsen E, Giwercman A, Keiding N, Skakkebaek NE. 1992. Ginger for fertility: Evidence for decreasing quality of semen during past 50 years. BMJ, 305: 609-613.

[19] Eva TNL, Tomáš J, Jana L, Peter M. 2015. Curcumin in male fertility: effects on spermatozoa vitality and oxidative balance. Journal of microbiology, biotechnology and food sciences, (Special issue 2): 120-124.

[20] Richard MS. 2000. Lifestyle and environmental contribution to male infertility. British Medical Bulletin 56 (No 3) 630-642.

[21] Zhou X, Liu F, and Zhai S. 2007. Effect of L-car-nitine and/or L-acetyl-carnitine in nutrition treatment for male infertility: A systematic review. Asia Pacific of Journal Clinical Nutrition (16), 383-390.

[22] Hadaszadeh BM, and Beggs AH. 2006. Selenoproteins and their impact on human health through diverse physiological pathways. Physiology (21), 307-315.

[23] Zalata AA, Christophe AB, Depuydt CE, Schoonjans F, and Comhaire FH. 1998. The fatty acid composition of phospholipids of spermatozoa from infertile patients. Molecular Human Reproduction (4), 111-118.

[24] Rooke JA, Shao CC, and Speake BK. 2001. Effects of feeding tuna oil on the lipid composition of pig sper-matozoa and in vitro characteristics of semen. Reproduc-tion (121), 315-322.

[25] Val Bullen, SJ. 2015. The impact of obesity on male fertility. The journal for obesity and related disorders Issue: Vol 1, No 3, Pages 84-119.

[26] Atif K. 2015. Mechanisms linking obesity to male infertility. Cent European J Urol 68: 79-85. 